\title{
Plant flavonoid taxifolin inhibits the growth, migration and invasion of human osteosarcoma cells
}

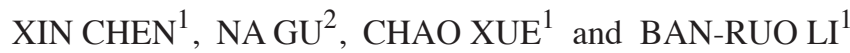 \\ Departments of ${ }^{1}$ Orthopedics and ${ }^{2}$ Respiratory Medicine, Hanzhong Centre Hospital, \\ Hanzhong, Shaanxi 723000, P.R. China
}

Received January 9, 2016; Accepted May 17, 2017

DOI: $10.3892 / \mathrm{mmr} .2017 .8271$

\begin{abstract}
The aim of the present study was to investigate the anti-cancer effects of the natural plant flavonoid, taxifolin, on human osteosarcoma cancer cells. Taxifolin was demonstrated to exhibit anti-cancer effects on U2OS and Saos-2 osteosarcoma cell lines. Treatment of cells with taxifolin inhibited proliferation and diminished colony formation in soft agar in a dose-dependent manner. In vivo, intraperitoneal administration of taxifolin in nude mice bearing U2OS xenograft tumors, significantly inhibited tumor growth. In addition, taxifolin treatment was demonstrated to promote $\mathrm{G}_{1}$ cell cycle arrest and cell apoptosis in U2OS and Saos-2 cell lines, as demonstrated by flow cytometry analysis. Western blot analysis demonstrated that taxifolin treatment was associated with a reduction in the expression levels of AKT serine/threonine kinase 1 (AKT), phosphorylated (p-Ser473) AKT, v-myc avian myelocytomatosis viral oncogene homolog (c-myc) and S-phase kinase associated protein 2 (SKP-2) in U2OS and Saos-2 cell lines. Overexpression of AKT considerably reversed the taxifolin-induced decrease in AKT, c-myc and SKP-2 protein expression and the decrease in AKT phosphorylation, suggesting that inactivation of AKT was a mediator of taxifolin-induced inhibition of c-myc and SKP-2. Furthermore, overexpression of SKP-2 in U2OS cells partially reversed the growth inhibition mediated by taxifolin. Finally, taxifolin treatment repressed cell migration and invasion in U2OS cells and this effect was markedly reversed by SKP-2 overexpression. The results of the present study indicate that taxifolin may present a potential novel therapeutic agent for osteosarcoma treatment.
\end{abstract}

\section{Introduction}

Cancer is one of the leading causes of mortality worldwide. Among the various types of cancer, osteosarcoma is one of the

Correspondence to: Dr Ban-Ruo Li, Department of Orthopedics, Hanzhong Centre Hospital, 22 Kangfu Road, Hantai, Hanzhong, Shaanxi 723000, P.R. China

E-mail: libanruo12@hotmail.com

Key words: taxifolin, U2OS, Saos-2, osteosarcoma, tumor most commonly diagnosed primary bone tumors, often occurring in children and adults and arising in the metaphysis $(1,2)$. Since the systemic spread of osteosarcoma is common, the prognosis for affected patients is poor (3). Previously, combination chemotherapy was demonstrated to substantially increase the survival rates of osteosarcoma patients by $60-70 \%$ (4); however, $40 \%$ of osteosarcoma patients still exhibit a poor response. A high risk of recurrence and metastasis exists despite thorough chemotherapy treatment and curative resection of the tumor (5). Failure of chemotherapy is primarily due to drug resistance. Therefore, an improved understanding of the molecular mechanisms underlying osteosarcoma invasion, as well as the development of novel potential treatments, are necessary for osteosarcoma therapy.

Chemoprevention is the pharmacological use of synthetic compounds or phytochemicals that prevent or reverse carcinogenesis or tumor development. Flavonoids are a class of phytochemical agents that are rich in naturally occurring polyphenolic compounds. They are abundant in medicinal herbs, vegetables, fruits and nuts. Flavonoids comprise of flavones, isoflavones, flavanones, flavonols, chalcones and anthocyanins $(6,7)$. The functions of dietary flavonoids in the prevention and treatment of cancer have been studied extensively in clinical trials and laboratory studies $(7,8)$. The chemical structure of flavonoids is similar to that of quercetin, and flavonoids have been reported to exhibit multiple pharmacological activities $(6,8)$. The biochemical function of flavonoids and their corresponding metabolites depend on the precise chemical structure of the compound and the relative positioning of different functional groups in the molecule.

Taxifolin (Fig. 1) is a characteristic plant flavonoid, which naturally occurs in onion (8), citrus fruits, and milk thistle. Taxifolin, isolated from the barks of Cedrus brevifolia, Cedrus brevifolia (Hooker fil.), Laric siberica (ledeb.) and Texus chinensis, has long been used in the treatment of cerebrovascular and cardiovascular disorders (9). Taxifolin, also known as dihydroquercetin, exhibits strong antioxidant abilities Taxifolin, also known as dihydroquercetin, exhibits strong antioxidant ability (10). The properties of taxifolin are similar to quercetin, which has been demonstrated to induce apoptosis in cell and animal models $(10,11)$.

Previous studies have demonstrated that taxifolin exerts multiple biological effects, including anti-oxidative, anti-inflammatory, anti-proliferative and anti-coagulative 
effects (12,13). Rogovskiı̌ et al (14) demonstrated that taxifolin exerts anti-proliferative properties in human breast cancer cells and in murine fibroblasts. In addition, Vrba et al (15) demonstrated that mitogen activated protein kinase and protein kinase C-dependent signal transduction is regulated and maintained by taxifolin. However, to the best of the author's knowledge, no studies performed to date have assessed the in vitro and in vivo anti-cancer effects of taxifolin in osteosarcoma. Therefore, the aim of the current study was to investigate the anti-cancer properties of taxifolin in osteosarcoma. To achieve this, the effect of taxifolin on the viability and proliferation of U2OS and Saos-2 osteosarcoma cells was evaluated, and the signaling factors involved in mediating these effects were investigated.

\section{Materials and methods}

Reagents. Taxifolin was purchased from Shanghai Huicheng Technology Ltd. (Shanghai, China). MTT, cell culture dishes and Hoechst 33258 were purchased from Sigma-Aldrich; Merck KGaA (Darmstadt, Germany). Matrigel was purchased from BD Biosciences (Franklin Lakes, NJ, USA). The primary antibodies, mouse monoclonal anti-Akt serine/threonine kinase 1 (Akt1; cat. no. sc-135829; 1:1,200), rabbit polyclonal anti-phosphorylated (p-Ser473) Akt (cat. no. sc-7985-R, 1:1,000), mouse monoclonal anti-v-myc avian myelocytomatosis viral oncogene homolog (c-myc; cat. no. sc-70469, 1:800), mouse monoclonal anti-S-phase kinase associated protein 2 [SKP-2; cat. no. sc-74477 (p45), 1:1,000] and mouse and rabbit monoclonal anti- $\beta$-actin (cat. no. sc-8432/sc-130656, 1:1,000) as well as secondary antibody, rabbit anti-mouse IgG HRP (cat. no. sc-358914, 1:10,000) were obtained from Santa Cruz Biotechnology, Inc. (Dallas, TX, USA).

Cell culture. The human osteosarcoma cell lines, U2OS and Saos-2, were obtained from the American Type Cell Culture Collection (Manassas, VA, USA). These cell lines were cultured in Dulbecco's modified Eagle's medium (DMEM; Invitrogen; Thermo Fisher Scientific, Inc., Waltham, MA, USA) supplemented with $10 \%$ fetal bovine serum, $1 \%$ penicillin-streptomycin and $1 \mathrm{mM}$ L-glutamine (Invitrogen; Thermo Fisher Scientific, Inc.) in a humidified incubator with $5 \% \mathrm{CO}_{2}$ and $95 \%$ air at $37^{\circ} \mathrm{C}$.

Cell proliferation assay. Cells (U20S/Saos-2) were cultured at a density of $4 \times 10^{3}$ cells/well in 96 -well plates for $24 \mathrm{~h}$. Increasing concentrations of taxifolin $(0,5,10,25$ and $50 \mu \mathrm{M})$ were then added to the cells in $100 \mu 1$ additional medium, and cells were cultured for a further $96 \mathrm{~h}$. The medium was removed by aspiration and $100 \mu \mathrm{l}$ water was added into the wells and stored overnight at $-80^{\circ} \mathrm{C}$. Plates were then thawed at $37^{\circ} \mathrm{C}$, and cells were stained by the addition of buffer containing $10 \mathrm{mM}$ Tris (pH 7.4) and $1 \mathrm{mM}$ EDTA with Hoechst $33258(0.2 \%)$ dye at $37^{\circ} \mathrm{C}$ for $1 \mathrm{~h}$. The relative DNA content was assayed by measuring Hoechst 33258 fluorescence using a Wallac 1420 Victor2 Multilabel microplate reader (Perkin Elmer Inc., Waltham, MA, USA) at excitation and emission wavelengths of 355 and $460 \mathrm{~nm}$, respectively (16).

MTT assay. Cell viability was measured using the MTT assay. U2OS and Saos-2 cells were seeded at a density of
$4 \times 10^{3}$ cells/well in 96-well plates for $24 \mathrm{~h}$, and then treated with increasing concentrations of taxifolin (0-50 $\mu \mathrm{M})$ for a further $48 \mathrm{~h}$. A total of $50 \mu \mathrm{l}$ MTT solution $(2 \mathrm{mg} / \mathrm{ml})$ was added to each well, and plates were incubated for $4 \mathrm{~h}$. The plates were then centrifuged at $1,000 \times \mathrm{g}$ for $5 \mathrm{~min}$ at $37^{\circ} \mathrm{C}$, to remove unconverted MTT and to leave the resulting formazan crystals at the bottom of the plates. The crystals were then dissolved in $100 \mu$ l dimethyl sulfoxide (DMSO), and the absorbance was read at $570 \mathrm{~nm}$ using a Titertek Multiskan MCC/340 plate reader (Titertek-Berthold, Berthold Detection Systems GmbH, Pforzheim, Germany). The results were presented as a relative percentage of the untreated control cells (17).

Flow cytometry. U2OS and Saos-2 cells were seeded at $6 \times 10^{6}$ cells/dish in $100 \mathrm{~mm}$ dishes and cultured for $24 \mathrm{~h}$ prior to taxifolin treatment. Cells were treated with taxifolin $(50 \mu \mathrm{M})$ and incubated for $48 \mathrm{~h}$. Cells were then fixed using $70 \%$ ice-cold ethanol diluted in phosphate-buffered saline (PBS) for $\sim 12 \mathrm{~h}$ at $37^{\circ} \mathrm{C}$. Following fixation, cells were washed with PBS and incubated with PBS containing RNase A $(0.1 \mathrm{mg} / \mathrm{ml}$; Sigma-Aldrich; Merck KGaA) for $30 \mathrm{~min}$ at $4^{\circ} \mathrm{C}$, before they were resuspended in $50 \mu \mathrm{g} / \mathrm{ml}$ propidium iodide (Sigma-Aldrich; Merck KGaA). The cell cycle distribution was determined using a BD FACScan flow cytometer (BD Biosciences) and the data were analyzed using the BD CellQuest Pro software program (version 5.1; BD Biosciences).

Soft agar assay. In order to determine soft agar colony formation, $6 \times 10^{3}$ U2OS and Saos-2 cells were diluted in complete DMEM medium containing agar $(0.3 \%)$ in $35-\mathrm{mm}$ cell culture plates. The cells were cultured for 3 weeks in a $5 \% \mathrm{CO}_{2}$ incubator at $37^{\circ} \mathrm{C}$ and treated with different concentration of taxifolin $(0,25$ and $50 \mu \mathrm{M})$. The colonies were stained with crystal violet $(0.5 \mathrm{mg} / \mathrm{ml})$ for $10 \mathrm{~h}$ at $37^{\circ} \mathrm{C}$.

Tumor xenografts. A total of 16 male BALB/c nude mice (age, 6-8 weeks; weight, 15-18 g) were procured from the National Cancer Institute at Frederick, Laboratory Animal Sciences Program (Frederick, MD, USA). BALB/c nude mice were maintained in a steel cage, under a 12-h dark/light cycle with free access to food and water. All the mice were subcutaneously injected with $5 \times 10^{3}$ U2OS cells suspended in Matrigel $(0.5 \mathrm{ml})$, and tumor growth was monitored weekly from 1 week post-injection. Mice were divided into control ( 8 mice with 14 tumors) and drug-treated (8 mice with 13 tumors) groups. At 21 days post-inoculation, mice in the drug-treated group were administered with $25 \mathrm{mg} / \mathrm{kg}$ taxifolin intraperitoneally (i.p) once every 2 days for remaining 24 days. The control mouse group was administered with an equal volume of saline (vehicle). The treatment was terminated at 45 days post-inoculation. Tumor size was measured using calipers and tumor volume was calculated using the following formula: Volum $\mathrm{e}=$ length $\mathrm{x}$ width $\mathrm{x}$ height $\mathrm{x} 0.52$ (18). Mouse body weight and tumor volumes were expressed as the mean \pm standard deviation (SD). The present study was approved by the Ethics Committee of Hanzhong Centre Hospital (HCH-4665; Hanzhong, China).

Western blot analysis. U2OS and Saos-2 cells $\left(1 \times 10^{4}\right)$ were treated with different concentrations of taxifolin $(0,25$ and 


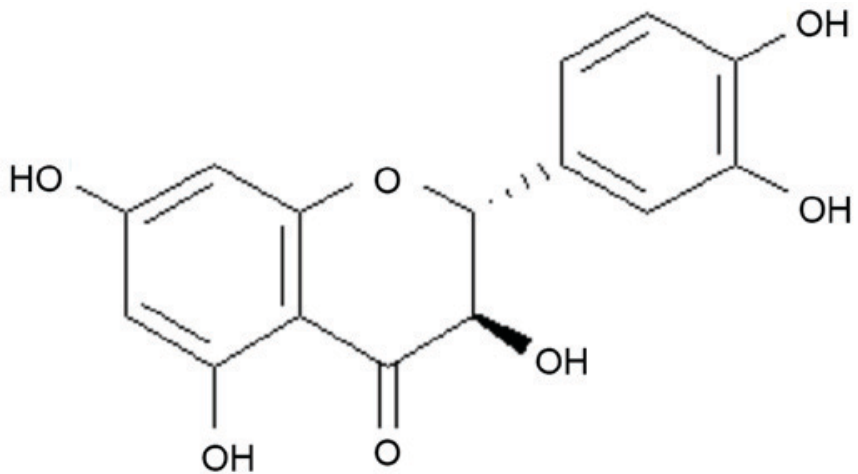

Figure 1. Chemical structure of taxifolin.

A

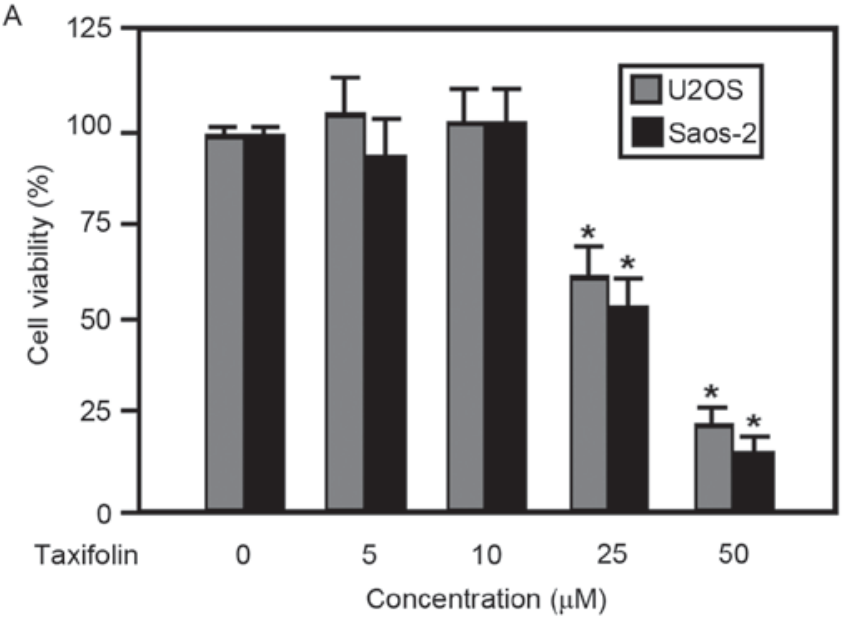

B

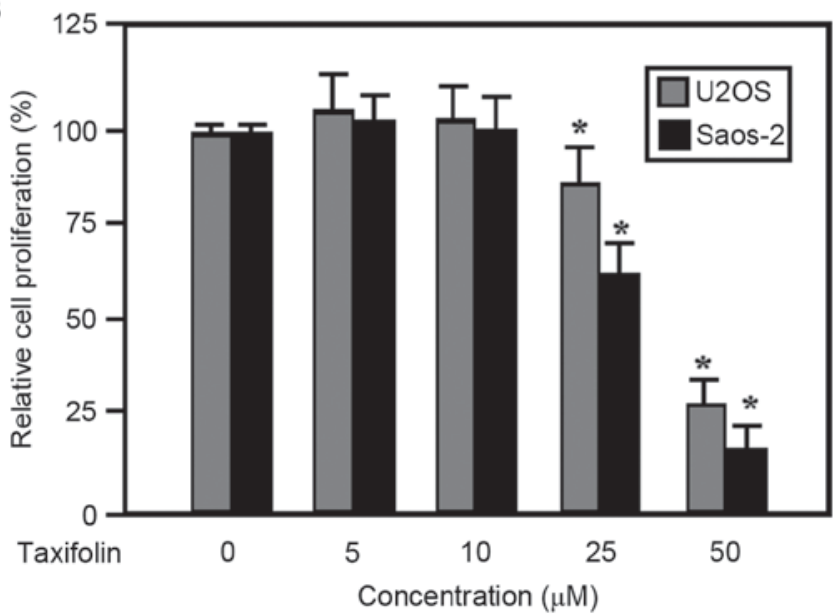

Figure 2. Effect of taxifolin on the viability and proliferation of osteosarcoma cells. U2OS and Saos-2 cells were treated with $0,5,10,25$ or $50 \mu \mathrm{M}$ taxifolin for $48 \mathrm{~h}$. (A) Cell viability was measured using an MTT assay. (B) Cell proliferation was measured by Hoechst 33258 staining. Cell numbers were normalized to untreated control cells, and the results are presented as the mean + standard deviation from triplicate measurements. ${ }^{*} \mathrm{P}<0.01$ vs. untreated cells $(0 \mu \mathrm{M})$.

$50 \mu \mathrm{M}$ ) for $72 \mathrm{~h}$ at $37^{\circ} \mathrm{C}$ and lysed using lysis buffer containing $0.5 \%$ sodium deoxycholate, $50 \mathrm{mM}$ Tris- $\mathrm{HCl}$ ( $\mathrm{pH} 7.5), 150 \mathrm{mM}$ $\mathrm{NaCl}, 1 \%$ nonidet P-40, $0.1 \%$ SDS, $1 \mathrm{mM}$ dithiothreitol,
$5 \mathrm{mM}$ EDTA, $50 \mathrm{mM}$ sodium fluoride, and $10 \mu \mathrm{g} / \mathrm{ml}$ aprotinin by incubating for $1 \mathrm{~h}$ at $37^{\circ} \mathrm{C}$. The resultant cell lysates were centrifuged at $3,000 \times \mathrm{g}$ for $10 \mathrm{~min}$ at $37^{\circ} \mathrm{C}$ and total cellular protein concentration was determined using a $\mathrm{BCA}$ protein assay kit (BioVision, Inc., Milpitas, CA, USA). Protein extracts $(\sim 60 \mu \mathrm{g})$ were separated by $10 \%$ SDS-PAGE and electrotransferred onto polyvinylidene difluoride membranes. The membrane was blocked with TBS containing Tween-20 and $5 \%$ skimmed milk for $2 \mathrm{~h}$ at $37^{\circ} \mathrm{C}$ and incubated with primary antibodies against Akt, p-S473-Akt, c-myc, SKP-2 and $\beta$-actin at $4^{\circ} \mathrm{C}$ overnight, followed by probing with secondary antibody for $2 \mathrm{~h}$ at $37^{\circ} \mathrm{C}$. Detection of bands was performed using an enhanced chemiluminescence detection kit (GE Healthcare Life Sciences, Chalfont, UK), and band densities were measured using Scion Image software (version 4.0) from Scion Co. (Frederick, MD, USA).

Overexpression of AKT and SKP-2. U2OS cells $\left(5 \times 10^{5}\right)$ were plated in 6-well plates for $24 \mathrm{~h}$ prior transfection and then U2OS cells were transfected with SKP-2 and AKT overexpression plasmids $(1 \mu \mathrm{M})$ like pcDNA3.1-SKP2, pcDNA3.1-AKT (designed by Nanjing Keygen Biotech Co., Ltd., Nanjing, China) and an empty vector (pcDNA3.1) using Lipofectamine 2000 (Thermo Fisher Scientific, Inc.), for $24 \mathrm{~h}$. Finally the transfected cells were treated with 0 or $25 \mu \mathrm{M}$ of taxifolin for $48 \mathrm{~h}$. Transfection of U2OS cells with the empty pcDNA3.1 vector served as a negative control (19).

Transwell migration assay. Briefly, U2OS cells $\left(1 \times 10^{4}\right)$ were plated in 6-well plates for $24 \mathrm{~h}$ prior to transfection. Cells were treated with 0,25 and $50 \mu \mathrm{M}$ taxifolin for $48 \mathrm{~h}$, then trypsinized (centrifuged at $600 \mathrm{x} \mathrm{g}$ for $10 \mathrm{~min}$ at $37^{\circ} \mathrm{C}$ ) and washed with PBS to remove adherent cells. A total of $1 \times 10^{3}$ treated cells diluted in $200 \mu 1$ serum-free DMEM were added to the upper compartment of transwell migration chambers (BD Biosciences), and DMEM containing 10\% FBS was added to the lower compartment. The chambers were then incubated at $37^{\circ} \mathrm{C}$ overnight. Cells that had migrated to the underside of the transwell filters were fixed with $70 \%$ methanol and stained with $10 \%$ Giemsa solution at room temperature for $1 \mathrm{~h}$. Filters were washed with water and quantification was performed by analyzing 6 random fields and counting the number of cells on the filter (lower side) under phase contrast microscopy at a magnification of $\mathrm{x} 200$.

Transwell invasion assay. For the invasion assays, Matrigel-coated transwell chambers were used (BD Biosciences). A total of U2OS cells $\left(1 \times 10^{5}\right)$ were plated in 6-well plates for $24 \mathrm{~h}$ prior to transfection. Cells were then treated with 0,25 , and $50 \mu \mathrm{M}$ taxifolin for $48 \mathrm{~h}$, and trypsinized (by centrifuging at $600 \mathrm{x} \mathrm{g}$ for $10 \mathrm{~min}$ at $37^{\circ} \mathrm{C}$ to remove adherent cells) and washed with PBS. Then the $1 \times 10^{4}$ taxifolin-treated U2OS cells were diluted in $200 \mu \mathrm{l}$ serum-free DMEM and added to the upper compartment of Matrigel-coated transwell chambers (BD Biosciences). DMEM containing 10\% FBS was added to the lower chamber before the plates were incubated overnight. The non-invaded cells were removed and the invaded cells on the underside of the filters were fixed with $70 \%$ methanol at $37^{\circ} \mathrm{C}$ for $1 \mathrm{~h}$. Filters were washed with water and stained with $10 \%$ Giemsa solution for $1 \mathrm{~h}$ at $37^{\circ} \mathrm{C}$. 
A

Taxifolin $(\mu \mathrm{M}) \quad 0$

U2OS

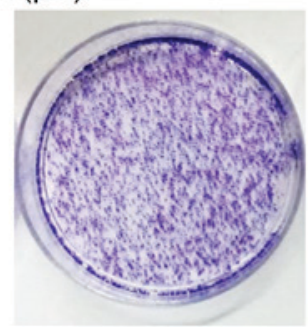

25

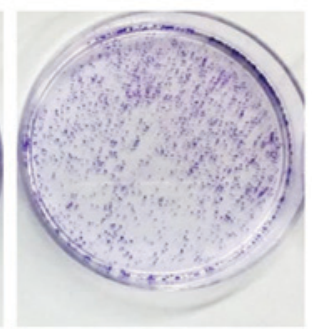

25

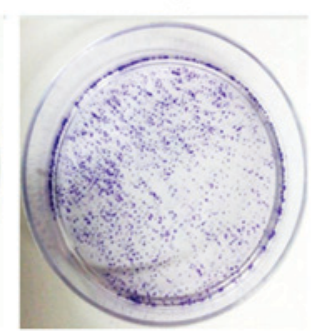

50

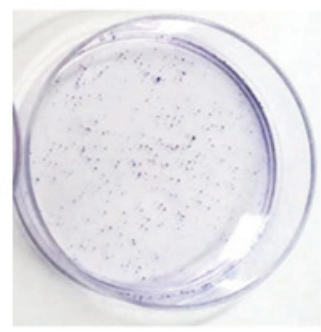

50

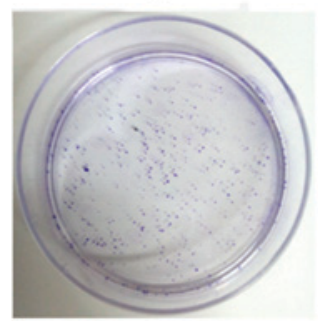

Figure 3. Effect of taxifolin on soft agar colony formation. (A) U2OS and (B) Saos-2 cells were treated with 0,25 or $50 \mu \mathrm{M}$ taxifolin for 3 weeks. Images depict representative results from three independent measurements.

A

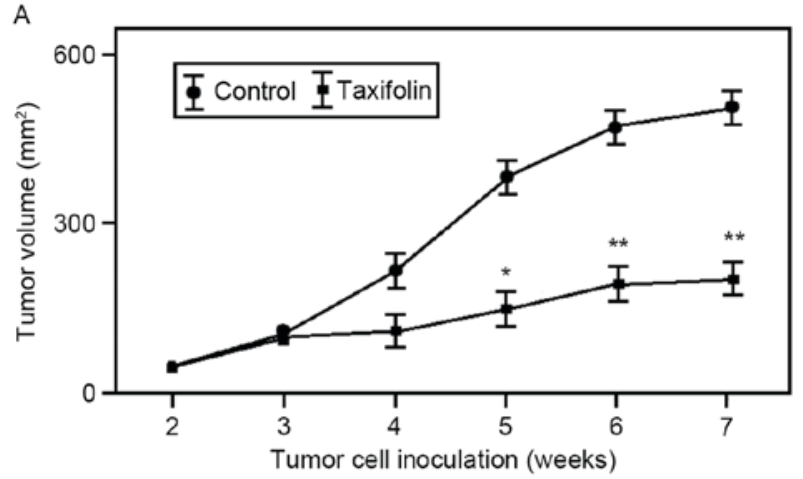

B

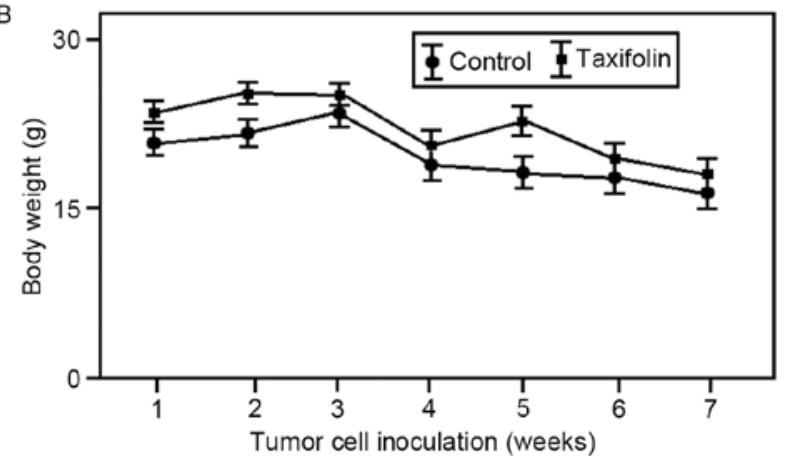

Figure 4. Effect of taxifolin on tumor growth in vivo. Xenograft tumors derived from intraperitoneal injection of U2OS cells were established in nude mice, and $25 \mathrm{mg} / \mathrm{kg}$ taxifolin or a vehicle control was administered at 1 week post-inoculation for a total of 7 weeks. (A) Tumor volumes and (B) the body weight of mice were measured weekly, and the results are presented as the mean \pm standard deviation $(\mathrm{n}=8) .{ }^{*} \mathrm{P}<0.05,{ }^{* *} \mathrm{P}<0.01$ vs. untreated control cells.

The number of invaded cells was quantified by counting the number of cells on the filter (6 random fields) under phase contrast microscopy at a magnification of $\mathrm{x} 200$.
Statistical analysis. Experimental results are expressed as the mean \pm SD. Differences among groups were examined for statistical significance using one-way analysis of variance followed by Dunnett's multiple comparison post hoc test on SPSS software (version 21.0, IBM Corp., Armonk, NY, USA). $\mathrm{P}<0.05$ was considered to indicate a statistically significant difference.

\section{Results}

Effect of taxifolin on the viability and proliferation of osteosarcoma cells. The viability and proliferation of taxifolin-treated human U2OS and Saos-2 osteosarcoma cells were examined using MTT and Hoechst 33258 assays, respectively. Results from the MTT assay demonstrated that the viability of U2OS and Saos-2 cells was inhibited by taxifolin treatment in a dose-dependent manner at concentrations $\geq 25 \mu \mathrm{M}$ compared with the untreated cells (Fig. 2A). In addition, taxifolin treatment suppressed the proliferation of U2OS and Saos-2 cells in a dose-dependent manner at concentrations $\geq 25 \mu \mathrm{M}$ when compared with the untreated cells (Fig. 2B). The half maximal effective concentration of taxifolin was similar for cell viability and proliferation (data not shown), suggesting that the observed decrease in cell viability may have been due to the suppression of cell proliferation.

Effect of taxifolin on soft agar colony formation. The anchorage-independent growth of U2OS and Saos-2 cells was examined using a soft agar colony formation assay. The colony formation results demonstrated that treatment with 25 and $50 \mu \mathrm{M}$ taxifolin markedly suppressed the ability of U2OS and Saos-2 cells to form colonies when compared with the untreated cells (Fig. 3). These results suggest a potential anti-tumor effect of taxifolin. 

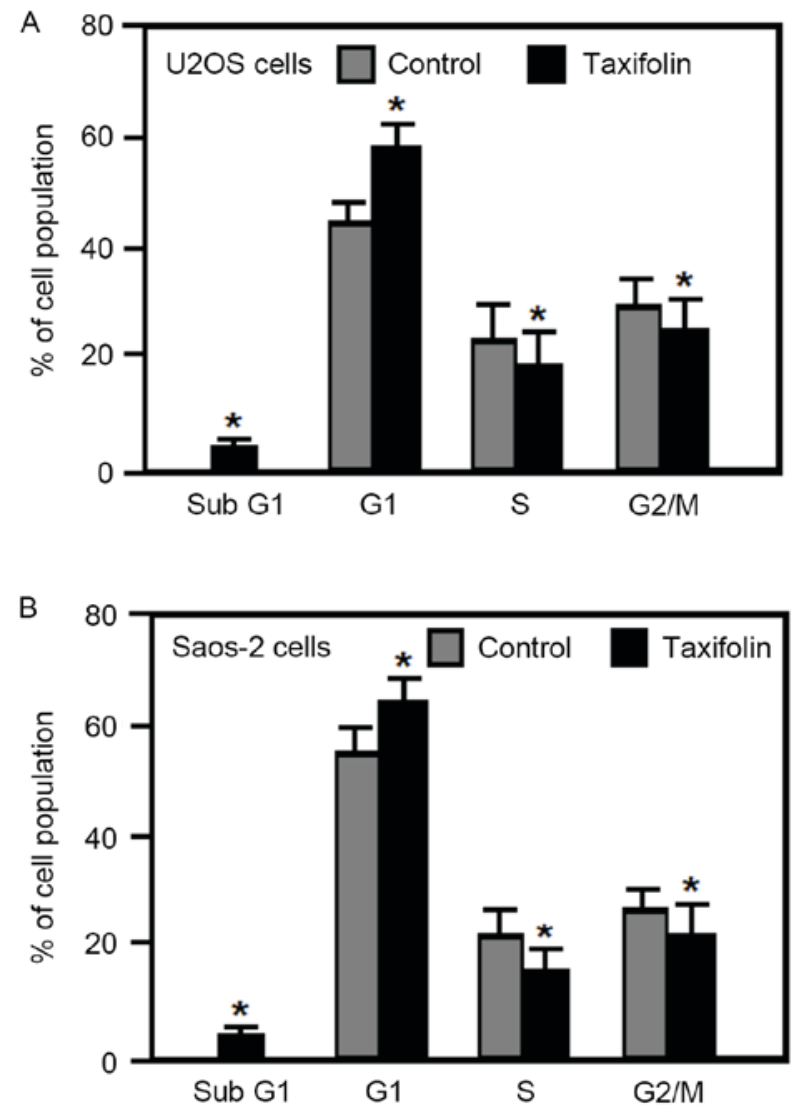

Figure 5. Effect of taxifolin on the cell cycle distribution and apoptosis of osteosarcoma cells. (A) U2OS and (B) Saos-2 cells were treated with 0 or $25 \mu \mathrm{M}$ taxifolin for $48 \mathrm{~h}$, and analyzed for cell cycle phase distribution by flow cytometry. Data are presented as the mean + standard deviation from four independent experiments. "P<0.05 vs. untreated cells.

Effect of taxifolin treatment on osteosarcoma tumor growth in vivo. In order to determine whether taxifolin treatment inhibits tumor growth in vivo, $\mathrm{U} 2 \mathrm{OS}$ cells were used to generate tumor xenograft models in nude mice. As demonstrated in Fig. 4A, intraperitoneal administration of taxifolin $(25 \mathrm{mg} / \mathrm{kg}$ once every 2 for 24 days) was associated with a $55 \%$ reduction $(\mathrm{P}<0.01)$ in the mean volume of $\mathrm{U} 2 \mathrm{OS}$ xenograft tumors at the end of the experiment (45 days). The body weight of untreated and taxifolin-treated mouse groups was gradually reduced but not significantly altered (Fig. 4B). These results suggest that taxifolin treatment inhibited osteosarcoma tumor growth in vivo.

Effect of taxifolin on cell cycle distribution and apoptosis. The effect of taxifolin on the cell cycle was examined in human osteosarcoma U2OS and Saos-2 cells by flow cytometry analysis. Treatment of U2OS and Saos-2 cells with $25 \mu \mathrm{M}$ taxifolin for $48 \mathrm{~h}$ significantly increased the percentage of cells in the $\mathrm{G}_{1}$ phase, and significantly reduced the percentage of cells in the $\mathrm{S}$ and $\mathrm{G}_{2} / \mathrm{M}$ phases when compared with untreated cells (Fig. 5). In addition, taxifolin treatment increased the percentage of U2OS and Saos-2 cells in the sub- $\mathrm{G}_{1}$ fraction (cells undergoing apoptosis) when compared with untreated cells (Fig. 5). These results demonstrated that taxifolin treatment induced $\mathrm{G}_{1}$ cell cycle arrest and increased apoptosis in osteosarcoma U2OS and Saos-2 cells.

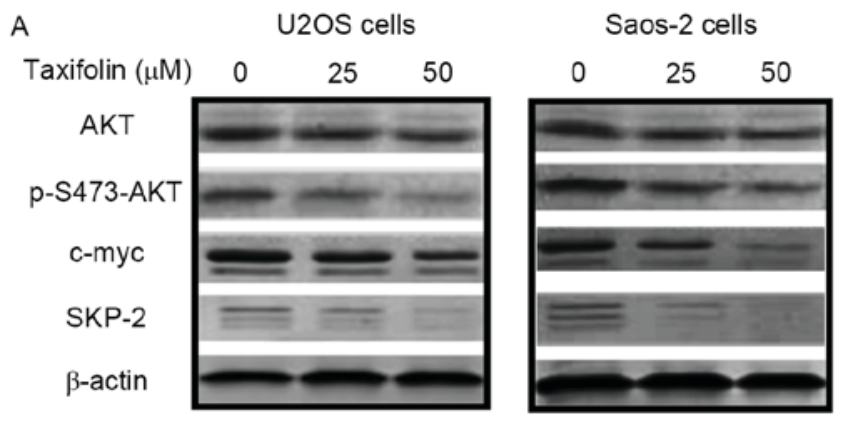

B

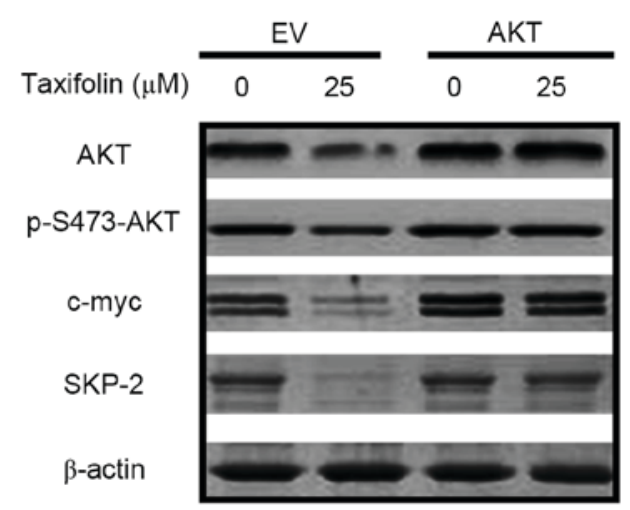

Figure 6. Effect of taxifolin on the expression of cell cycle proteins. The protein expression levels of AKT, p-Ser473-AKT, c-myc, SKP-2 and $\beta$-actin were determined by western blotting in (A) U2OS and Saos-2 cells treated with 0,25 or $50 \mu \mathrm{M}$ taxifolin for $48 \mathrm{~h}$, and (B) in U2OS cells transfected with an EV or AKT-overexpressing vectors for $24 \mathrm{~h}$, followed by treatment with with 0 or $25 \mu \mathrm{M}$ taxifolin for $48 \mathrm{~h}$. AKT, AKT serine/threonine kinase 1; p-S473-AKT, phosphorylated AKT at Ser 473; c-myc, v-myc avian myelocytomatosis viral oncogene homolog; SKP-2, S-phase kinase associated protein $2 ; \mathrm{EV}$, empty vector.

Effect of taxifolin on the expression of cell cycle-associated proteins. Western blot analysis was performed to determine whether taxifolin treatment altered the expression of proteins involved in cell cycle regulation. Taxifolin treatment markedly reduced the protein expression levels of AKT, p-Ser473-AKT, c-myc and SKP-2 in U2OS and Saos-2 cells when compared with untreated cells (Fig. 6A). Transfection of U2OS cells with empty pcDNA3.1 plasmids or the pcDNA3.1-AKT vector was performed in order to overexpress AKT and investigate its association with c-myc and SKP-2. As demonstrated in Fig. 6B, overexpression of AKT markedly reversed the taxifolin-induced repression of p-AKT, c-myc and SKP-2 protein expression levels, indicating that decreased AKT expression may mediate taxifolin-induced c-myc and SKP-2 inhibition. These results revealed that taxifolin reduced the expression levels of signaling factors implicated in cell cycle regulation, potentially via the AKT signaling pathway.

Effect of SKP-2 overexpression. As demonstrated in Fig. 6A, taxifolin treatment resulted in a gradual reduction in SKP-2 expression levels in U2OS and Saos-2 cells. Therefore the effect of SKP-2 overexpression on taxifolin-induced anti-cancer properties was examined further. SKP-2 overexpression in U2OS cells (Fig. 7A) partially inhibited the taxifolin-induced decrease in cell viability when compared with cells transfected with empty vectors (Fig. 7B). The migration and invasion 
A

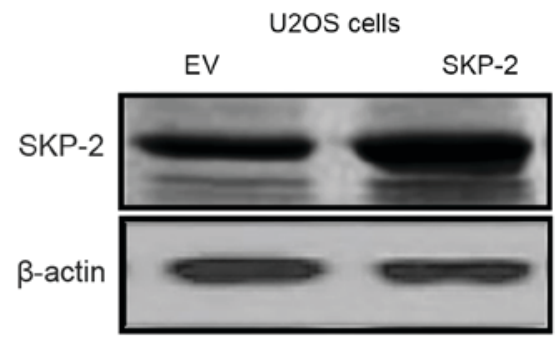

C

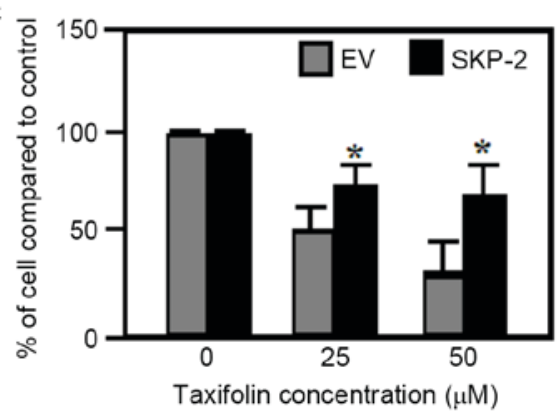

B

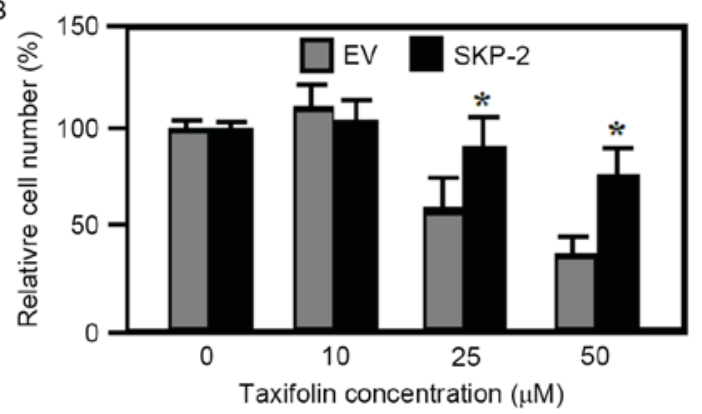

D

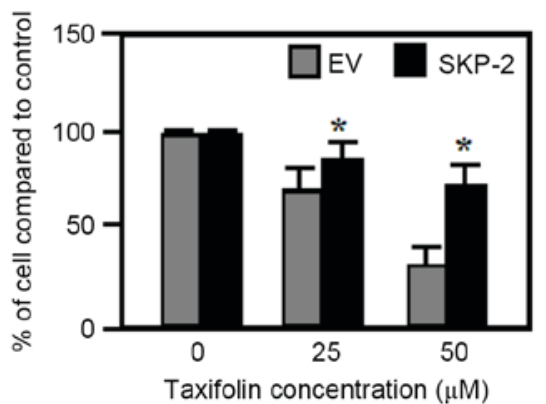

Figure 7. SKP-2 overexpression reverses the effects of taxifolin on osteosarcoma cells. U2OS cells were transfected with an EV or a SKP-2 overexpressing vector, then treated with taxifolin for $48 \mathrm{~h}$. (A) SKP-2 protein expression levels were measured by western blotting to confirm SKP-2 overexpression. (B) Cell viability was measured using an MTT assay. (C) Cell migration was measured using a transwell migration assay. (D) Cell invasion was measured using a Matrigel-coated transwell invasion assay. SKP-2, S-phase kinase associated protein 2 ; EV, empty vector. "P<0.05 vs. untreated cells $(0 \mu \mathrm{M})$.

of U2OS cells transfected with empty vector plasmids were markedly reduced by taxifolin treatment when compared with untreated cells (Fig. 7C and D). By contrast, overexpression of SKP-2 significantly attenuated the taxifolin-mediated reduction in U2OS cell migration and invasion when compared with empty vector-transfected cells (Fig. 7C and D). As overexpression of SKP-2 was not observed to eliminate the inhibitory effects taxifolin completely, it is possible that additional mechanisms or signaling pathways, other than AKT/SKP-2, may be triggered by taxifolin in osteosarcoma cell lines.

\section{Discussion}

Flavonoids exhibit a broad range of pharmacological and biological effects, with chemoprevention as one of their most characterized effects $(6,8)$. In the present study, the anti-cancer properties of taxifolin were investigated in human U2OS and Saos-2 osteosarcoma cell lines. Treatment of osteosarcoma cells with taxifolin resulted in $\mathrm{G}_{1}$ cell cycle arrest and increased apoptosis. Results from the MTT assay, and transwell migration and invasion assays revealed that taxifolin treatment inhibited cell viability, as well as the migration and invasion abilities of human osteosarcoma cells. In addition, the soft agar colony formation assay revealed that taxifolin decreased the anchorage-independent growth of osteosarcoma cells. Furthermore, taxifolin treatment suppressed the expression of c-myc and SKP-2, and the inactivation of AKT may have been responsible for these taxifolin-mediated alterations in c-myc and SKP-2 expression. In vivo studies demonstrated that taxifolin administration significantly inhibited tumor growth in mice bearing U2OS cell-derived xenograft tumors. These results indicate that taxifolin may present an effective agent for the treatment of osteosarcoma.
In order to examine the mechanisms underlying the anti-tumor effects of taxifolin further, western blotting analysis was performed. The results indicated that the protein expression levels of AKT, p-AKT (Ser473), c-myc and SKP-2 were markedly reduced in U2OS and Saos-2 osteosarcoma cells treated with taxifolin when compared to untreated cells. Phosphatidylinositol 3-kinase (PI3K)/AKT signaling activation is important during cell proliferation and the progression of osteosarcoma (20). In addition, AKT is an important regulator of cell survival pathways by inhibiting apoptosis, and its kinase activation is mediated by Ser473 phosphorylation. Overexpression of proteins in the PI3K/AKT signaling pathway is associated with a poor clinical prognosis (21-23).

$\mathrm{C}$-myc is a major transcriptional regulator. It is a multi-functional proto-oncogene and a nuclear phosphoprotein that mediates cell proliferation, cell cycle arrest and apoptosis (24). Abnormal c-myc mRNA expression promotes the invasion of osteosarcoma cells (25) and leads to cancer development $(26,27)$, whereas c-myc protein attenuation leads to diminished cell proliferation and tumor growth in osteosarcoma (28). Abnormal c-myc function has been identified in stomach, breast, colon and lung cancers (29). Therefore, c-myc is considered to be a promising anti-cancer drug target (30). In the present study, taxifolin treatment suppressed AKT, p-AKT (Ser473) and c-myc protein expression, suggesting that c-myc repression may mediate the inhibitory effects of taxifolin on cell growth.

SKP-2 serves an important role in regulating the activation of cyclin-dependent kinase inhibitor 1B (CDKN1B; also known as $\left.\mathrm{p} 27^{\mathrm{Kip} 1}\right)$, as well as in regulating ubiquitin-dependent processes $(31,32)$. CDKN1B inhibits cell proliferation by inducing cell cycle arrest at the $G_{1}$ phase (33). In the present study, taxifolin treatment of U2OS and Saos-2 cells reduced 
SKP-2 expression, promoted $\mathrm{G}_{1}$ cell cycle arrest and induced apoptosis. SKP-2 overexpression partially inhibited the taxifolin-induced reduction in U2OS cell viability, migration and invasion, suggesting that SKP-2 suppression may be a major factor in taxifolin-mediated growth inhibition of osteosarcoma cell lines. As overexpression of SKP-2 did not completely reverse taxifolin-mediated cell growth inhibition, it is possible that additional signaling pathways may be induced by taxifolin to inhibit osteosarcoma cell growth.

In conclusion, the results of the present study revealed that taxifolin treatment inhibited the proliferation, migration and invasion of U2OS and Saos-2 human osteosarcoma cell lines, potentially via AKT and SKP-2 signaling pathways. The results suggest that taxifolin may present an effective therapeutic agent for the treatment of osteosarcoma.

\section{Acknowledgements}

This study was financially aided by Hanzhong Centre Hospital, Shaanxi, China (grant no. HCH-17392/16).

\section{References}

1. Duong LM and Richardson LC: Descriptive epidemiology of malignant primary osteosarcoma using population-based registries, United States, 1999-2008. J Registry Manag 40: 59-64, 2013.

2. Savage SA, Woodson K, Walk E, Modi W, Liao J, Douglass C, Hoover RN and Chanock SJ; National Osteosarcoma Etiology Study Group: Analysis of genes critical for growth regulation identifies insulin-like growth factor 2 receptor variations with possible functional significance as risk factors for osteosarcoma. Cancer Epidemiol Biomarkers Prev 16: 1667-1674, 2007.

3. Longhi A, Errani C, De Paolis M, Mercuri M and Bacci G: Primary bone osteosarcoma in the pediatric age: State of the art Cancer Treat Rev 32: 423-436, 2006.

4. Longhi A, Fabbri N, Donati D, Capanna R, Briccoli A, Biagini R, Bernini G, Ferrari S, Versari M and Bacci G: Neoadjuvant chemotherapy for patients with synchronous multifocal osteosarcoma: Results in eleven cases. J Chemother 13: 324-330, 2001.

5. Collins M, Wilhelm M, Conyers R, Herschtal A, Whelan J, Bielack S, Kager L, Kühne T, Sydes M, Gelderblom H, et al: Benefits and adverse events in younger versus older patients receiving neoadjuvant chemotherapy for osteosarcoma: Findings from a meta-analysis. J Clin Oncol 31: 2303-2312, 2013.

6. Middleton E Jr, Kandaswami C and Theoharides TC: The effects of plant flavonoids on mammalian cells: Implications for inflammation, heart disease, and cancer. Pharmacol Rev 52: 673-751, 2000.

7. Dajas F, Rivera F, Blasina F, Arredondo F, Echeverry C, Lafon L, Morquio A and Heizen H: Cell culture protection and in vivo neuroprotective capacity of flavonoids. Neurotox Res 5: 425-432, 2003.

8. Slimestad R, Fossen T and Vågen IM: Onions: A source of unique dietary flavonoids. J Agric Food Chem 55: 10067-10080, 2007.

9. Guo H, Zhang X, Cui Y, Zhou H, Xu D, Shan T, Zhang F, Guo Y, Chen Y and Wu D: Taxifolin protects against cardiac hypertrophy and fibrosis during biomechanical stress of pressure overload. Toxicol Appl Pharmacol 287: 168-177, 2015.

10. Liang L, Gao C, Luo M, Wang W, Zhao C, Zu Y, Efferth T and Fu Y: Dihydroquercetin (DHQ) induced HO-1 and NQO1 expression against oxidative stress through the Nrf2-dependent antioxidant pathway. J Agric Food Chem 61: 2755-2761, 2013.

11. Zhang ZR, Al Zaharna M, Wong MM, Chiu SK and Cheung HY: Taxifolin enhances andrographolide-induced mitotic arrest and apoptosis in human prostate cancer cells via spindle assembly checkpoint activation. PLoS One 8: e54577, 2013.

12. Kim YJ, Choi SE, Lee MW and Lee CS: Taxifolin glycoside inhibits dendritic cell responses stimulated by lipopolysaccharide and lipoteichoic acid. J Pharm Pharmacol 60: 1465-1472, 2008.
13. Ahn JY, Choi SE, Jeong MS, Park KH, Moon NJ, Joo SS, Lee CS, Choi YW, Li K, Lee MK, et al: Effect of taxifolin glycoside on atopic dermatitis-like skin lesions in NC/Nga mice. Phytother Res 24: 1071-1077, 2010.

14. Rogovskiǔ VS, Matiushin AI, Shimanovskiǔ NL, Semeřkin AV, Kukhareva TS, Koroteev AM, Koroteev MP and Nifant'ev EE: Antiproliferative and antioxidant activity of new dihydroquercetin derivatives. Eksp Klin Farmakol 73: 39-42, 2010 (In Russian).

15. Vrba J, Gažák R, Kuzma M, Papoušková B, Vacek J, Weiszenstein M, Křen V and Ulrichová J: A novel semisynthetic flavonoid 7-O-galloyltaxifolin upregulates heme oxygenase-1 in RAW264.7 cells via MAPK/Nrf2 pathway. J Med Chem 56: 856-866, 2013.

16. Chuu CP and Lin HP: Antiproliferative effect of LXR agonists T0901317 and 22(R)-hydroxycholesterol on multiple human cancer cell lines. Anticancer Res 30: 3643-3648, 2010.

17. Wilson JK, Sargent JM, Elgie AW, Hill JG and Taylor CG: Feasibility study of the MTT assay for chemosensitivity testing in ovarian malignancy. Br J Cancer 62: 189-194, 1990.

18. Chuu CP, Kokontis JM, Hiipakka RA, Fukuchi J, Lin HP, Lin CY, Huo C, Su LC and Liao S: Androgen suppresses proliferation of castration-resistant LNCaP 104-R2 prostate cancer cells through androgen receptor, Skp2, and c-Myc. Cancer Sci 102: 2022-2028, 2011.

19. Ye J, Yin L, Xie P, Wu J, Huang J, Zhou G, Xu H, Lu E and He X: Antiproliferative effects and molecular mechanisms of troglitazone in human cervical cancer in vitro. Onco Targets Ther 8: 1211-1218, 2015.

20. Zhang A, He S, Sun X, Ding L, Bao X and Wang N: Wnt5a promotes migration of human osteosarcoma cells by triggering a phosphatidylinositol-3 kinase/Akt signals. Cancer Cell Int 14: $15,2014$.

21. Lin HP, Lin CY, Liu CC, Su LC, Huo C, Kuo YY, Tseng JC, Hsu JM, Chen CK and Chuu CP: Caffeic acid phenethyl ester as a potential treatment for advanced prostate cancer targeting akt signaling. Int J Mol Sci 14: 5264-5283, 2013.

22. Kreisberg JI, Malik SN, Prihoda TJ, Bedolla RG, Troyer DA, Kreisberg S and Ghosh PM: Phosphorylation of Akt (Ser473) is an excellent predictor of poor clinical outcome in prostate cancer. Cancer Res 64: 5232-5236, 2004.

23. Liu CC, Hsu JM, Kuo LK and Chuu CP: Caffeic acid phenethyl ester as an adjuvant therapy for advanced prostate cancer. Med Hypotheses 80: 617-619, 2013.

24. Kokontis J, Takakura K, Hay N and Liao S: Increased androgen receptor activity and altered c-myc expression in prostate cancer cells after long-term androgen deprivation. Cancer Res 54: 1566-1573, 1994.

25. Han G, Wang Y and Bi W: C-Myc overexpression promotes osteosarcoma cell invasion via activation of MEK-ERK pathway. Oncol Res 20: 149-156, 2012.

26. Edwards J, Krishna NS, Witton CJ and Bartlett JM: Gene amplifications associated with the development of hormone-resistant prostate cancer. Clin Cancer Res 9: 5271-5281, 2003.

27. Grad JM, Dai JL, Wu S and Burnstein KL: Multiple androgen response elements and a Myc consensus site in the androgen receptor (AR) coding region are involved in androgen-mediated up-regulation of AR messenger RNA. Mol Endocrinol 13: 1896-1911, 1999.

28. Liu Z, Zhang G, Li J, Liu J and Lv P: The tumor-suppressive microRNA-135b targets c-myc in osteoscarcoma. PLoS One 9: e102621, 2014

29. Field JK and Spandidos DA: The role of ras and myc oncogenes in human solid tumours and their relevance in diagnosis and prognosis (review). Anticancer Res 10: 1-22, 1990.

30. Matthews GM, Lefebure M, Doyle MA, Shortt J, Ellul J, Chesi M, Banks KM, Vidacs E, Faulkner D, Atadja P, et al: Preclinical screening of histone deacetylase inhibitors combined with ABT-737, rhTRAIL/MD5-1 or 5-azacytidine using syngeneic Vk*MYC multiple myeloma. Cell Death Dis 4: e798, 2013

31. Carrano AC, Eytan E, Hershko A and Pagano M: SKP2 is required for ubiquitin-mediated degradation of the CDK inhibitor p27. Nat Cell Biol 1: 193-199, 1999.

32. Tsvetkov LM, Yeh KH, Lee SJ, Sun H and Zhang H: p27(Kip1) ubiquitination and degradation is regulated by the SCF (Skp2) complex through phosphorylated Thr187 in p27. Curr Biol 9: 661-664, 1999.

33. Elledge SJ and Harper JW: Cdk inhibitors: On the threshold of checkpoints and development. Curr Opin Cell Biol 6: 847-852, 1994. 